\title{
İnce Film Hidrasyon ve Mikrofluidizasyon Yöntemleri Kullanılarak Polifenollerin Yüksek Verimle Nanokapsüllere Yüklenmesi
}

\author{
Mine Gültekin-Özgüven ${ }^{*}$, Kadriye Nur Kasapoğlu² ${ }^{2}$ Ceren Güngör ${ }^{3}$, Esra Nur Ertürk ${ }^{4}$, Beraat Özçelik ${ }^{5,6}$ \\ 1* İstanbul Teknik Üniversitesi, Kimya-Metalurji Fakültesi, Gıda Mühendisliği Bölümü, İstanbul, Türkiye (ORCID: 0000-0002-2073-8075), gultekinmi@itu.edu.tr \\ ${ }^{2}$ İstanbul Teknik Üniversitesi, Kimya-Metalurji Fakültesi, Gıda Mühendisliği Bölümü, İstanbul, Türkiye (ORCID: 0000-0001-6070-4948), kasapogluk@itu.edu.tr \\ 3 İstanbul Teknik Üniversitesi, Kimya-Metalurji Fakültesi, Gıda Mühendisliği Bölümü, İstanbul, Türkiye (ORCID: 0000-0001-9572-066), gungorceren5@ gmail.com \\ 4 İstanbul Teknik Üniversitesi, Kimya-Metalurji Fakültesi, Gıda Mühendisliği Bölümü, İstanbul, Türkiye (ORCID: 0000-0003-0558-580), erturkkesraa@ gmail.com \\ 5 İstanbul Teknik Üniversitesi, Kimya-Metalurji Fakültesi, Gıda Mühendisliği Bölümü, İstanbul, Türkiye (ORCID: 0000-0002-1810-8154), ozcelik@itu.edu.tr \\ ${ }^{6}$ BIOACTIVE Research \& Innovation Food Manufac. Indust. Trade Ltd., Teknokent ARI-3, İstanbul, Türkiye (ORCID: 0000-0002-1810-8154), ozcelik@itu.edu.tr
}

(Illk Geliş Tarihi 1 Haziran 2021 ve Kabul Tarihi 15 Ağustos 2021)

(DOI: $10.31590 /$ ejosat.946290)

ATIF/REFERENCE: Gültekin-Özgüven, M., Kasapoğlu, K. N., Güngör, C., Ertürk, E. N. \& Özçelik, B. (2021). İnce Film Hidrasyon ve Mikrofluidizasyon Yöntemleri Kullanılarak Polifenollerin Yüksek Verimle Nanokapsüllere Yüklenmesi. Avrupa Bilim ve Teknoloji Dergisi, (25), 758-762.

\section{$\ddot{\mathbf{O} z}$}

$\mathrm{Bu}$ çalışmada, fenolikçe zengin siyah kuşburnu meyvesi ekstraktı ince film hidrasyon ve mikrofluizidasyon yöntemleri birlikte kullanılarak nano boyuttaki lipozomlara yüksek verimle yüklenmiş̧ir. Hazırlanan nanolipozomların stabilitesinin arttırılması amacıyla negatif elektrik yüklü olan nanolipozomlar elektrostatik depozisyon tekniği ile pozitif yüklü bir biyopolimer olan kitosan ile kaplanmıştır. Bunun için farklı konsantrasyonlarda $(\% 0.1, \% 0.2, \% 0.3, \% 0.4$ ve \%0.5) çalışılarak optimum kaplama için gerekli kitosan konsantrasyonu araştırılmıştır. Bu amaçla, hazırlanan nanolipozom kapsülleri ortalama partikül boyutu ve zeta potansiyeli ölçümleri ile karakterize edilmiştir. Enkapsülasyon veriminin belirlenmesi için toplam fenolik madde içerikleri (TPC) -Folin Ciocalteu yöntemi ve antioksidan kapasiteleri (CUPRAC ve DPPH yöntemleri) analizleri gerçekleştirilmiştir. Çalışmada kullanılan \%0.1 kitosan konsantrasyonu hariç (çökme gözlendi) diğer kitosan konsantrasyonlarında (\%0.2, \%0.3, \%0.4 ve \%0.5) kaplama başarılı olmuş̧ur. En yüksek enkapsülasyon verimine \%0.3 kitosan konsantrasyonu ile kaplanan nanolipozomlarda ulaşılmıştır. Buna göre, enkapsülasyon verimi TPC'ye göre \%92, CUPRAC'a göre \%87, DPPH'e göre \%83 olarak belirlenmiştir. Sonuç olarak, ince film hidrasyon ve mikrofluizidasyon yöntemlerinin birlikte kullanılmasıyla yüksek enkapsülasyon verimli nanolipozom üretiminin mümkün olduğu anlaşılmıştır.

Anahtar Kelimeler: İnce Film Hidrasyon, Mikrofluidizasyon, Nanolipozom, Polifenol, Enkapsülasyon Verimi

\section{Loading Polyphenols into Nanocapsules with High Encapsulation Efficiency Using Thin Film Hydration and Microfluidization}

\begin{abstract}
In this study, phenolic-rich black rosehip fruit extract was loaded into nano-sized liposomes with high efficiency by using thin-film hydration and microfluidization methods together. In order to increase the stability of the prepared nanoliposomes, negatively charged nanoliposomes were coated with chitosan, a positively charged biopolymer, by electrostatic deposition technique. For this, the chitosan concentration required for optimum coating was investigated by working at different concentrations $(0.1 \%, 0.2 \%, 0.3 \%$, $0.4 \%$ and $0.5 \%$ ). For this purpose, the prepared nanoliposome capsules were characterized by mean particle size and zeta potential measurements. To determine the encapsulation efficiency, total phenolic content (TPC) by Folin Ciocalteu method and antioxidant capacity (CUPRAC and DPPH methods) analyzes were performed. Coating was successful at other chitosan concentrations $(0.2 \%$, $0.3 \%, 0.4 \%$ and $0.5 \%$ ), except for the $0.1 \%$ chitosan concentration (aggregation was observed). The highest encapsulation efficiency was achieved in nanoliposomes coated with $0.3 \%$ chitosan concentration. Accordingly, the encapsulation efficiency was determined as $92 \%, 87 \%$ and $83 \%$ in terms of TPC, CUPRAC and DPPH assays, respectively. In conclusion, it has been understood that it is possible to produce nanoliposomes with high encapsulation efficiency by combining the thin film hydration and microfluidization methods together.
\end{abstract}

Keywords: Thin Film Hydration, Microfluidization, Nanoliposome, Polyphenol, Encapsulation Efficiency

* Sorumlu Yazar: gultekinmi@itu.edu.tr 


\section{Giriş}

Doğal antioksidanların gida sistemlerinde kullanılmasına yönelik pek çok kısıtlama mevcuttur. Polifenollerin düşük çözünürlükleri ile $\mathrm{pH}$, yüksek sıcaklık, oksijen, ve 1 şık gibi çevresel faktörlere karşı dayanımlarının zayıf olması, bu maddelerin gıda proseslerinden kaynaklanan kayıplarının fazla olmasına neden olmaktadır. Benzer şekilde, polifenollerin sindirim koşullarındaki stabiliteleri de düşüktür (Fang \& Bhandari, 2010). Enkapsülasyon yöntemleri, bu bileşiklerin koruyucu küresel bir matris/ çeper içerisine yerleştirilmek suretiyle muhafaza edilerek yukarıda bahsedilen sorunların üstesinden gelmek için çok güçlü bir araçtır (Dordevic ve diğ. 2015). Oluşan kapsüller kaplanan biyoaktif bileşen ve duvar materyali arasında fiziksel bir bariyer işlevi göstererek nem, $\mathrm{pH}$ ve oksitlenme gibi dış zararlara karşı koruma sağlar (de Vos ve diğ., 2010).

Lipozomlar, kolesterol ve toksik olmayan doğal fosfolipidlerden oluşturulabilen küresel şekilli küçük yapay veziküllerdir. Lipozomlar, hem hidrofobik hem de hidrofilik karakterde olmaları nedeniyle pek çok bioaktif bileşen için uygun taşıyıcı sistemlerdir (Akbarzadeh ve diğ., 2013). Biyouyumlu ve biyo-bozunur olmaları, toksisite göstermemeleri ve kapsüllenmiş biyoaktif maddeyi kontrollü salma gibi özellikleri sayesinde son yıllarda tarım, gıda ve ilaç sanayiinde kullanım alanlarını arttırmıştır (Laye ve diğ., 2008; Gibis ve diğ., 2012). Ayrıca, doğada var olan ingrediyenlerden elde edilmesi gidalarda kullanımında herhangi bir yasal düzenlemeye gerek bırakmamaktadır (Taylor ve diğ., 2005). Gıda uygulamalarında soya, ayçiçeği, yumurta lesitini veya birden fazla farklı fosfolipidler kullanılarak lipozomlar hazırlanabilir. Lesitinler uzun yıllardır çeşitli gıda formülasyonlarında emülgatör olarak kullanılmaktadır ve Amerikan Gıda ve İlaç Dairesi'ne (FDA) göre Genellikle Emniyetli Kabul Edilebilen (GRAS) kategorisinde yer almaktadırlar (Kırtıl \& Öztop, 2014).

Lipozomlar kapsül içerisine aldıkları biyoaktif bileşenlerinin ortamla etkileşimini ortadan kaldırarak stabilitelerini arttırıp daha uzun süre aktivitelerinin korunmasına yardımcı olmaktadır (Chun ve diğ., 2013). Ancak, lipozomların kırılgan bir yapıya sahip olmaları nedeniyle içlerindeki enkapsüle edilmiş olan maddenin sızma olasılığı bulunmaktadır (Laye ve diğ., 2008). Diğer taraftan, lipozomlar kıvrımlı olmadıkları zaman en düşük enerji seviyesindedirler. Bu nedenle küçük lipozomlar kıvrımlarını azaltmak için bir araya gelip birleşme eğilimindedirler. Bunun sonucunda da lipozomların partikül boyutlarının zamanla artması nedeniyle zamanla lipozomlar çökelti oluşturup dispersiyondan ayrılmaktadır. Yani lipozomlar termodinamik olarak stabil olmayan yapılardır (Gibis ve diğ., 2012). Diğer taraftan, fosfolipidlerin okside olması da lipozom stabilitesini engelleyebilmektedir. Lipozom stabilitesini artırmak için kullanılan en yaygın yöntem lipozomların kitosan, aljinat ve pektin gibi elektriksel olarak karşıt yüklü başka bir biyopolimer ile kaplanmasıdır (Chun ve diğ., 2013).

Etanol injeksiyon, ince film hidrasyonu, ters faz evaporasyonu gibi konvansiyonel yöntemlerle yüksek enkapsülasyon verimli lipozomlar elde edilebilmektedir. Lipozomların üretiminde en eski ve yaygın kullanılan yöntem Bangham metodu olarak da bilinen ince film hidrasyonu olup, temelde fosfolipidlerin organik çözgende çözülerek, sonrasında çözgen ayrıştırılıp kalan ince film tabakasının hidratlanmak suretiyle kendiliğinden lipozom veziküllerinin oluşturulmasına dayanır (Esposto ve diğ., 2021; Trucillo ve diğ., 2020).

Elde edilen konvansiyonel lipozomların boyutunu küçültmek için sonikasyon, mikrofluidizasyon, yüksek basınçlı ekstrüzyon gibi tekniklerden yararlanmak mümkündür. Aslında lipozomlar ve nanolipozomlar fiziksel ve termodinamik olarak benzer olsa da nanolipozomların konvensiyonel lipozomlara göre daha küçük boyutta olmaları ve daha yüksek yüzey/hacim oranı nanolipozomların biyoyararlılığını arttırmaktadır. Mikrofluidizasyon tekniği, lipozomların boyutlarını istenen şekilde küçültmesinin yanı sıra toksik solventler kullanmadan büyük ölçekli lipozom üretimine uygundur (Zou ve diğ., 2014). Burada vurgulanan noktalardan yola çıkarak bu çalışmanın amacı siyah kuşburnu meyvesinden elde edilen polifenollerce zengin etanol ekstraktının ince film hidrasyon yöntemini takiben mikrofluizidasyon tekniği kullanılarak hazırlanan nanolipozomlara yüksek enkapsülasyon verimini hedefleyerek enkapsüle edilmesi ve bu nanolipozomların kitosanla kaplanarak stabilitesinin arttırılmasıdır. Bu amaçla, elde edilen nanolipozom kapsülleri ortalama partikül boyutu ve zeta potansiyeli analizleri yapılarak karakterize edilip optimum enkapsülasyon koşulları tespit edilmiştir. Enkapsülasyon verimini hesaplamak için ise toplam fenolik madde içeriği (Folin-Ciocalteu yöntemi) ve antioksidan kapasite (CUPRAC ve DPPH yöntemleri) analizleri gerçekleştirilmiştir.

\section{Materyal ve Metot}

\subsection{Materyal}

$\mathrm{Bu}$ çalışmada kullanılan tüm kimyasallar analitik saflıkta olup Sigma-Aldrich'ten (St. Louis, MO) satın alınmıştır. Siyah kuşburnu meyvesi ise Bayburt yöresinden temin edilmiştir.

\subsection{Metot}

\subsubsection{Polifenol Ekstraktının Hazırlanması}

Sıvı azot kullanılarak dondurulan siyah kuşburnu meyveleri elektrikli ögütücü kullanılarak toz haline getirildikten sonra etanol kullanılarak ekstrakte edilmiştir. Bunun için, $1 \mathrm{~g}$ öğütülmüş meyvenin üzerine $10 \mathrm{~mL}$ etanol eklenerek ultrasonikatörle 2 dakika süreyle muamele edilmiştir. Daha sonra, karışım $7168 g^{\prime}$ de $5^{\circ} \mathrm{C}^{\prime}$ de 10 dakika süreyle santrifüj edilerek etanol fazı katı kısımdan ayrılmıştır. İşlem üç defa tekrarlanmış olup elde edilen etanol fazları birleştirilmiştir. Son olarak, etanol $40^{\circ} \mathrm{C}$ 'de vakum altında döner buharlaştırıcı (Büchi) yardımıyla uzaklaştırılmıştır.

\subsubsection{Polifenol Ekstraktının İnce Film Hidrasyon Yöntemi ve Mikrofluidizasyon Kullanılarak Nanolipozomal Enkapsülasyonu}

Lipozomlar ince film hidrasyonu yöntemine göre Yang ve diğ. (2011) tarafından tarif edildiği gibi hazırlanmıştır. Buna göre, $0.1 \mathrm{~g}$ ekstrakt, $800 \mathrm{mg}$ fosfolipit ve $200 \mathrm{mg}$ kolesterol tartılıp üzerine $10 \mathrm{ml}$ kloroform eklenip iyice karıştırıldıktan sonra kloroform $\mathrm{k} 1 \mathrm{sm} 150^{\circ} \mathrm{C}$ 'de döner buharlaştırıcıda uçurulmuştur. Oluşan ince filmin üstüne $400 \mathrm{mg}$ Tween 80 ve 50 $\mathrm{ml}$ fosfat tampon çözeltisi ( $\mathrm{pH} 4.0$ ) eklenmiştir.

Ultrasonikatör yardımıla homojenize edildikten sonra oluşan dispersiyon mikrofluidizerden (Microfluidizer Processor M-110L, Microfluidics, Newton, ABD) 25,000 psi basınçta 5 defa geçirilerek polifenol ekstraktı içeren nanolipozomlar elde edilmiştir. Ayrıca, kontrol olarak ekstrakt içermeyen boş nanolipozomlar da benzer şekilde üretilmiştir.

\subsubsection{Nanokapsüllerin Kitosanla Kaplanması}

Elde edilen boş ve ekstrakt içeren nanolipozomlar negatif yüklü oldukları için pozitif yüklü kitosan polimeri ile tabakatabaka yöntemine göre Özgüven ve diğg. (2020)'nin tarif ettiği şekilde kaplanmıştır. Bunun için kitosan farklı konsantrasyonlarda $(\% 0.2, \% 0.4, \% 0.6, \% 0.8$ ve $\% 1.0 \mathrm{w} / \mathrm{v})$ hazırlandıktan sonra üretilen nanolipozom dispersiyonları ile 
karıştırıldıktan sonra bir gece boyunca manyetik karıştırıcıda karıştırılmıştır.

\subsubsection{Nanokapsüllerin Karakterizasyonu}

Elde edilen nanokapsüllerin karakterizasyonu için zeta potansiyeli ve ortalama partikül boyutu (Mastersizer 2000, Malvern Instruments, Malvern, United Kingdom) ölçülmüştür.

\subsubsection{Enkapsülasyon Verimi}

Nanolipozomlara tutuklanan ekstraktın enkapsülasyon verimini hesaplamak için Gültekin-Özgüven ve diğ. (2016)'nın tarif ettiği şekilde jel filtrasyon yöntemi kullanılmıştır. Sephadex G50'nin fosfat tamponda oluşturduğu jelden geçirilen ekstrakt içeren nanolipozomlardan enkapsüle olmayan ekstrakt ve bunların kitosan kaplı hallerinden bağlanmamış kitosan kısımları jelde tutularak uzaklaştırılır. Daha sonra, jelden geçen nanolipozomlar ise \%0.15'lik Triton X-100 çözeltisi kullanılarak parçalanır. Yapılan işlemin prensibi, lipozomu parçalayarak, lipozomların yüzeyindeki ve içindeki fenolik bileşiklerin açığa çıkarılması ilkesine dayanmaktadır.

\subsubsection{Toplam Fenolik Madde Miktarı}

Toplam fenolik madde miktarını belirlemek için FolinCiocalteu metodu kullanılmıştır (Gültekin-Özgüven ve diğ., 2016). Seyreltilmiş ekstrakt içeren nanolipozom örneklerinden 200'er $\mu$ l alınarak üzerine 1.5 ml 1:10 oranında seyreltilmiş Folin-Ciocalteu reaktifi eklenmiştir. Daha sonra bu karışıma 1.2 ml \%7.5'luk sodyum karbonat eklenerek karıştırılmış ve 45 dakika karanlık bir ortamda bekletilmiştir. Oluşan renk spektrofotometrede $765 \mathrm{~nm}$ dalga boyunda okunmuştur. Boş lipozom örnekleri kontrol olarak kullanılmıştır. Sonuçlar gallik asit eşdeğeri (GAE) cinsinden mg GAE/100 ml ekstrakt olarak hesaplanmıştır.

\subsubsection{Toplam Antioksidan Kapasite}

Toplam antioksidan kapasite CUPRAC ve DPPH yöntemleri kullanılarak belirlenmiştir.

\subsubsection{CUPRAC Yöntemi}

Apak ve diğ. (2004)'nin yöntemine göre ekstrakt içeren nanolipozom örneklerinden 100 'er $\mu \mathrm{l}$ alınarak üzerine $1 \mathrm{ml}$ Bakır (II) klorit, $1 \mathrm{ml}$ Neocuproine ve $1 \mathrm{ml}$ sodyum asetat çözeltileri ve $1 \mathrm{ml}$ saf su ile karıştırılıp 30 dakika karanlıkta bekletilmiştir. Oluşan renk $450 \mathrm{~nm}$ dalga boyunda spektrofotometrede okutulmuştur. Boş lipozom örnekleri kontrol olarak kullanılmıştır. Sonuçlar Trolox eşdeğeri (TE) cinsinden $\mathrm{mg}$ TE/100g ml ekstrakt olarak hesaplanmıştır.

\subsubsection{DPPH Yöntemi}

Ekstrakt içeren nanolipozom örneklerinden 100'er $\mu$ l alınıp üzerine $2 \mathrm{ml}$ DPPH içeren metanol çözeltisi eklenerek vorteksle karıştırılması sağlanmıştır. 30 dakika karanlık bir ortamda bekletildikten sonra sonucu oluşan renk spektrofotometrede 517 $\mathrm{nm}$ dalga boyunda okutulmuştur (Altin ve diğ., 2018). Boş lipozom örnekleri kontrol olarak kullanılmıştır. Sonuçlar Trolox eşdeğeri (TE) cinsinden $\mathrm{mg}$ TE/100 ml ekstrakt olarak hesaplanmıştır.

\subsection{8. Ístatistiksel Analiz.}

İstatistiksel analizler IBM SPSS software (21.0, Chicago, IL, USA) kullanılarak gerçekleştirilmiştir. Tüm analizler en az 3 kere tekrarlanmıştır. Sonuçlar ortalama değerler ve standart sapma değerleri ile birlikte verilmiştir. Farklılıklar Tukey testi ile $P$ değeri $<0.05$ 'e göre değerlendirilmiştir.

\section{Araştırma Sonuçları ve Tartışma \\ 3.1. Nanokapsüllerin Karakterizasyonu}

Tablo 1'de görüldüğü gibi nanolipozomların karakterizasyonu için ortalama partikül boyutu ve elektriksel yükü belirten zeta potansiyeli ölçümlerinden yararlanılmıştır.
Nano boyutuna küçültülen boş lipozomlar elektriksel olarak negatif (-10.9) yüklüdür. Polifenol ekstraktı yüklenen nanolipozomların zeta potansiyelinin polifenol ekstraktının da negatif elektrik yüklü olmasından dolayı arttığı (-14.7) görülmektedir. Diğer taraftan, boş nanolipozomların partikül boyutunun da $85.6 \mathrm{~nm}$ 'den içine ekstrakt yüklendiğinde 93.9 nm'ye büyüdüğü belirlenmiştir.

Elektrostatik etkileşimler sayesinde nanolipozomlar kitosan polimeriyle kaplanmıştır. $\mathrm{Bu}$ nedenle, kitosanla kaplanan ekstrakt içeren ve içermeyen nanolipozomların zeta potansiyelinin negatiften pozitife geçmesi beklenmektedir. Nitekim boş nanolipozom için -10.90 ve ekstrakt içeren nanolipozom için $-14.70 \mathrm{mV}$ olan zeta potansiyeli kitosanla kaplanmasinın sonucunda sirasiyla en fazla 18.93 (\%0.4 konsantrasyonda) ve 15.76 (\%0.5 konsantrasyonda) $\mathrm{mV}$ 'a kadar değişmiştir. Bulgular literatürle (Akgün ve diğ., 2020; Gibis ve diğ., 2012) uyumludur. Ayrıca, nanolipozomların kitosanla kaplanmasının sonucunda partikül boyutunda da artış olmuştur. Boş nanolipozomların partikül boyutu $85.6 \mathrm{~nm}$ 'den en fazla 171.2 nm'ye kadar artmıştır. Benzer şekilde, ekstrakt içeren nanolipozomlar da 93.9 nm'den en fazla 161.3 nm'ye kadar artış göstermiştir. Buradan yola çıkarak, \%0.2'lik kitosan çözeltisi ile kaplanan ekstrakt içeren ve içermeyen nanolipozomlar hariç diğer tüm kitosan konsantrasyonlarında $(\% 0.2, \% 0.6, \% 0.8$ ve \%1.0) kitosanla kaplamanın başarılı olduğu anlaşılmıştır. Söz konusu konsantrasyonlar kullanılarak sirasıyla \%0.1, \%0.3, \%0.4 ve \%0.5 konsantrasyonlarında kitosanla kaplanmış nanolipozom kapsülleri elde edilmiş olur. \%0.1 konsantrasyonda kitosanla kaplama denemesinde çökme gözlenmiştir. \% 0.2 'den düşük kitosan konsantrasyonunun çökelti oluşumuna neden olduğu, lipozomların kaplanmasında uygun olmadığı başka çalışmalarda da bildirilmiştir ( $\mathrm{Li}$ ve diğ., 2015). Elde edilen kitosanla kaplanmış ekstrakt içeren ve içermeyen nanolipozomlardan yüksek zeta potansiyeline sahip ve düşük partikül boyutunda olanların en yüksek stabiliteye sahip olduğu söylenebilmektedir.

\subsection{Enkapsülasyon Verimi}

Enkapsülasyon veriminin hesaplanmasında toplam fenolik madde ile toplam antioksidan kapasite (CUPRAC ve DPPH) analizleri kullanılmıştır. Şekil 1'de verildiği gibi ekstrakt içeren nanolipozomların enkapsülasyon verimi TPC, CUPRAC ve DPPH sonuçlarına göre sırasıyla $\% 81, \% 80$ ve $\% 80$ olarak bulunmuştur. $\mathrm{Bu}$ enkapsülasyon verimi oldukça yüksektir ve literatür bilgileriyle de uyuşmaktadır (Akgün ve diğ., 2020; Gibis ve diğ., 2012; Gültekin-Özgüven ve diğ., 2016).

Polifenollerin lipozomlara tutuklanmalarında kullanılan lipozom hazırlama yöntemine göre farklı enkapsülasyon verimleri elde edilmektedir. Trucillo ve di ̆. (2018) zeytin fenoliklerinin enkapsülasyonunda süperkritik destekli prosesten yararlanarak en fazla \%58 enkapsülasyon verimine ulaşırken Paini ve diğ. (2015) sonikasyon işlemi sayesinde apigenini \%98 verimle enkapsüle edebilmiştir ve sonikasyon uygulamasının enkapsülasyon verimini arttırdığını rapor etmiştir.

$\% 0.3$ kitosanla kaplama yapıldıktan sonra nanolipozomların enkapsülasyon verimi TPC'ye göre $\% 92$, CUPRAC'a göre $\% 87$, DPPH'e göre \%83 olarak belirlenmiştir. Bunu TPC'ye göre $\% 83$, CUPRAC'a göre \%76, DPPH'e göre \%85 enkapsülasyon verimi ile \%0.4'lük kitosan kaplı ekstrakt içeren nanolipozomların takip etmektedir. Görüldüğü gibi ince film hidrasyon yöntemini takiben mikrofluizidasyon tekniği kullanılarak hazırlanan nanolipozom kapsüllerin enkapsülasyon verimi oldukça yüksektir. İnce film hidrasyon yöntemi ile sonikasyon tekniğinin kullanılarak kitosan kaplı kuersetin 
nanolipozomlarının enkapsülasyon verimi \% 71.14 olarak rapor edilmiştir (Hao ve diğ., 2017).

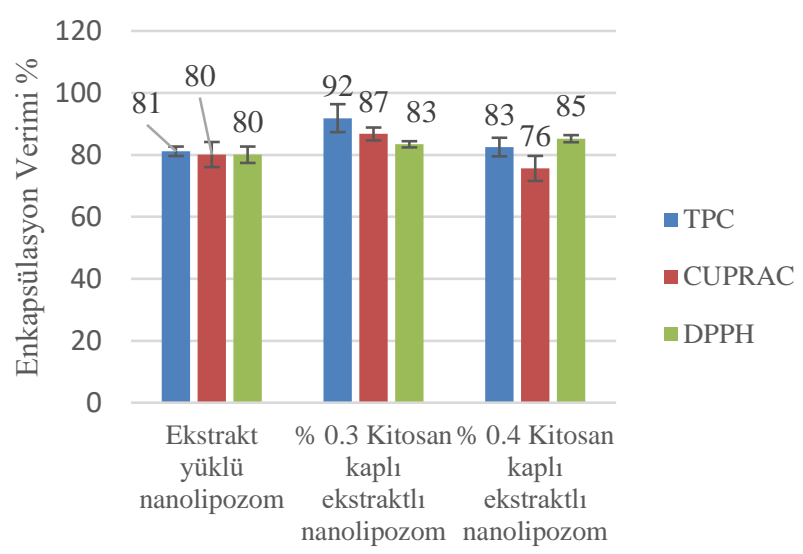

Şekil 1. Ekstrakt Yüklü Nanolipozom, \%0.3 Kitosan Kaplı Ekstraktll Nanolipozom ve \%0.4 Kitosan Kapll Ekstraktl Nanolipozomun \% Enkapsulasyon Verimleri.

Diğer taraftan, enkapsülasyon veriminin hesaplanmasında yararlanılan spektrofotometrik yöntemlerden ziyade HPLC gibi daha hassas sonuç veren cihazlar kullanılarak daha gerçekçi olarak hesaplanması da mümkün olacaktır (Paini ve diğ., 2015).

İstatistiksel olarak \%0.3 ve \%0.4 kitosan konsantrasyonu ile nanolipozomların kaplanmasında partikül boyutu ve zeta potansiyeli açısından fark görülmediğinden ( $>0.05)$ enkapsülasyon verimi daha yüksek olduğu için \%0.3'lük kitosan konsantrasyonu ile kaplanan nanolipozomların seçilmesinin daha uygun olduğu düşünülmektedir.

\section{Sonuç}

İnce film hidrasyon yöntemini izleyen mikrofluizidasyon sonucu elde edilen ve kitosanla kaplamanın (\%0.2, \%0.3, \%0.4,
\%0.5) başarılı olduğu ekstrakt içeren nanolipozomların enkapsülasyon verimleri dikkate alındığında \%0.3'lük kitosan çözeltisi ile kaplanan nanolipozomların toplam fenolik madde ve antioksidan kapasite (CUPRAC ve DPPH) açısından değerlendirildiğinde en yüksek enkapsülasyon verimine sahip olduğu belirlenmiştir. Ayrıca, \%0.3'lük kitosan konsantrasyonu kullanılarak kaplanan nanolipozomların partikül boyutu ve zeta potansiyeli açısından daha stabil oldukları anlaşılmıştır. Sonuç olarak ince film hidrasyon ve mikrofluizidasyon yöntemlerinin birlikte kullanılarak yüksek enkapsülasyon verimine sahip nanolipozom elde edilebileceği, elde edilen nanolipozomların kaplanmasında kullanılan kitosan polimeri ile geniş bir konsantrasyon aralığında (\%0.2-0.5) kaplama yapmanın mümkün olabileceği anlaşılmıştır. Diğer taraftan, ince film hidrasyon yönteminde etanol gibi çözgenlerden yararlanıldığı için bu yöntemin hidrofiliklerin yanı sıra hidrofobik ve lipofilik karakterdeki fenolik bileşiklerin enkapsülasyonunda da kullanılması söz konusu olabilmektedir. Bu nedenle, ince film hidrasyon yöntemi ve mikrofluizidasyon tekniğinin birlikte kullanılarak özellikle suda çözünürlüğü az olan hidrofobik veya lipofilik karakterdeki fenolik bileşiklerde denenmesi, elde edilen nanokapsüllerin özellikle biyoyararlılık ve stabiliteleri üzerine çalışmaların gerçekleştirilmesi önerilmektedir. Böylece suda çözünürlüğü az olan ancak yüksek antioksidan kapasitesi olan fenolikleri içeren kapsüllerin ileride gıda, besin takviyesi, kozmetik ve ilaçta kullanımlarının ilk çalışmaları gerçekleştirilmiş olacaktır.

\section{Teşekkür}

Yazarlar İstanbul Teknik Üniversitesi Gıda Mühendisliği Bölümü'nden Yüksek Gıda Mühendisi Evren Demircan'a desteklerinden dolayı teşekkür eder.

Tablo 1. Nanokapsüllerin Karakterizasyonu.

\begin{tabular}{lcc}
\hline \multicolumn{1}{c}{ Nanokapsüller } & Ortalama Partikül Boyutu (nm) & Zeta Potansiyeli (mV) \\
\hline Boş nanolipozom & $85.6 \pm 1.33^{\mathrm{f}}$ & $-10.90 \pm 1.27^{\mathrm{a}}$ \\
\% 0.1 Kitosan kaplı boş nanolipozom & Çöktü & - \\
\% 0.2 Kitosan kaplı boş nanolipozom & $180.9 \pm 7.53^{\mathrm{a}}$ & $13.96 \pm 1.11^{\mathrm{d}}$ \\
\% 0.3 Kitosan kaplı boş nanolipozom & $157.4 \pm 1.38^{\mathrm{b}}$ & $17.03 \pm 2.77^{\mathrm{e}}$ \\
\% 0.4 Kitosan kaplı boş nanolipozom & $171.2 \pm 2.62^{\mathrm{a}}$ & $18.93 \pm 0.80^{\mathrm{e}}$ \\
\% 0.5 Kitosan kaplı boş nanolipozom & $156.2 \pm 4.83^{\mathrm{c}}$ & $17.56 \pm 2.00^{\mathrm{e}}$ \\
& & $-14.70 \pm 0.58^{\mathrm{b}}$ \\
Ekstraktlı nanolipozom & $93.9 \pm 2.76^{\mathrm{e}}$ & - \\
\% 0.1 Kitosan kaplı ekstraktlı nanolipozom & $C ̧ \ddot{\mathrm{k} t u ̈}$ & $7.29 \pm 0.36^{\mathrm{c}}$ \\
\% 0.2 Kitosan kaplı ekstraktlı nanolipozom & $139.4 \pm 1.13^{\mathrm{d}}$ & $11.44 \pm 3.32^{\mathrm{d}}$ \\
\% 0.3 Kitosan kaplı ekstraktlı nanolipozom & $153.5 \pm 2.28^{\mathrm{c}}$ & $13.96 \pm 1.72^{\mathrm{d}}$ \\
\% 0.4 Kitosan kaplı ekstraktlı nanolipozom & $150.7 \pm 1.47^{\mathrm{c}}$ & $15.76 \pm 1.26^{\mathrm{d}}$ \\
\hline
\end{tabular}

Her kolondaki harfler istatistiksel olarak önemli farklılıklarl p<0.05 düzeyindeki farklılıklarl göstermektedir.

\section{Kaynakça}

Akbarzadeh, A., Rezaei-Sadabady, R., Davaran, S., Joo, S. W., Zarghami, N., Hanifehpour, Y., ... \& Nejati-Koshki, K. (2013). Liposome: classification, preparation, and applications. Nanoscale Research Letters, 8(1), 1-9.
Akgün, D., Gültekin-Özgüven, M., Yücetepe, A., Altin, G., Gibis, M., Weiss, J., \& Özçelik, B. (2020). Stirred-type yoghurt incorporated with sour cherry extract in chitosancoated liposomes. Food Hydrocolloids, 101, 105532. 
Altin, G., Gültekin-Özgüven, M., \& Ozcelik, B. (2018). Chitosan coated liposome dispersions loaded with cacao hull waste extract: Effect of spray drying on physico-chemical stability and in vitro bioaccessibility. Journal of Food Engineering, 223, 91-98.

Apak, R., Güçlü, K., Özyürek, M., \& Karademir, S. E. (2004). Novel total antioxidant capacity index for dietary polyphenols and vitamins $\mathrm{C}$ and $\mathrm{E}$, using their cupric ion reducing capability in the presence of neocuproine: CUPRAC method. Journal of Agricultural and Food Chemistry, 52(26), 7970-7981.

Chun, J.-Y., Choi, M.-J., Min, S.-G., \& Weiss, J. (2013). Formation and stability of multiple-layered liposomes by layer-by-layer electrostatic deposition of biopolymers. Food Hydrocolloids, 30(1), 249-257.

de Vos, P., Faas, M. M., Spasojevic, M., \& Sikkema, J. (2010). Encapsulation for preservation of functionality and targeted delivery of bioactive food components. International dairy journal, 20(4), 292-302.

Đorđević, V., Balanč, B., Belščak-Cvitanović, A., Lević, S., Trifković, K., Kalušević, A., ... \& Nedović, V. (2015). Trends in encapsulation technologies for delivery of food bioactive compounds. Food Engineering Reviews, 7(4), 452-490.

Esposto, B. S., Jauregi, P., Tapia-Blácido, D. R., \& Martelli-Tosi, M. (2020). Liposomes vs. chitosomes: Encapsulating food bioactives. Trends in Food Science \& Technology, 108, 4048.

Fang, Z., \& Bhandari, B. (2010). Encapsulation of polyphenolsa review. Trends in Food Science \& Technology, 21(10), 510-523.

Gibis, M., Vogt, E., \& Weiss, J. (2012). Encapsulation of polyphenolic grape seed extract in polymer-coated liposomes. Food Funct., 3(3), 246-254.

Gültekin-Özgüven, M., Karadağ, A., Duman, Ş., Özkal, B., \& Özçelik, B. (2016). Fortification of dark chocolate with spray dried black mulberry (Morus nigra) waste extract encapsulated in chitosan-coated liposomes and bioaccessability studies. Food Chemistry, 201, 205-212.

Hao, J., Guo, B., Yu, S., Zhang, W., Zhang, D., Wang, J., \& Wang, Y. (2017). Encapsulation of the flavonoid quercetin with chitosan-coated nano-liposomes. LWT-Food Science and Technology, 85, 37-44.

Kırtıl, E., \& Öztop, M. H. (2014). Enkapsülasyon maddesi olarak lipozom ve gidalarda kullanımı: Yapısı, karakterizasyonu, üretimi ve stabilitesi. Akademik Gida, 12(4), 41-57.

Laye, C., McClements, D. J., \& Weiss, J. (2008). Formation of Biopolymer-Coated Liposomes by Electrostatic Deposition of Chitosan. Journal of Food Science, 73(5), N7-N15.

Li, Z., Paulson, A. T., \& Gill, T. A. (2015). Encapsulation of bioactive salmon protein hydrolysates with chitosan-coated liposomes. Journal of Functional Foods, 19, 733-743.

Özgüven, M., Beyde, B., \& Özçelik, B. (2020). Atıkların Değerlendirmesi: Fındık (Corylus avellana L.) ve Antep Fıstığı (Pistacia vera L.) İç Zarlarından Elde Edilen Fenolikçe Zengin Ekstraktlara Lipozomal Taşıma Sistemlerinin Uygulanabilirliği. Avrupa Bilim ve Teknoloji Dergisi, (19), 241-246.

Paini, M., Daly, S. R., Aliakbarian, B., Fathi, A., Tehrany, E. A., Perego, P., ... \& Valtchev, P. (2015). An efficient liposome based method for antioxidants encapsulation. Colloids and Surfaces B: Biointerfaces, 136, 1067-1072.
Taylor, T. M., Weiss, J., Davidson, P. M., \& Bruce, B. D. (2005). Liposomal nanocapsules in food science and agriculture. Critical reviews in food science and nutrition, 45(7-8), 587605.

Trucillo, P., Campardelli, R., Aliakbarian, B., Perego, P., \& Reverchon, E. (2018). Supercritical assisted process for the encapsulation of olive pomace extract into liposomes. The Journal of Supercritical Fluids, 135, 152-159.

Trucillo, P., Campardelli, R., \& Reverchon, E. (2020). Liposomes: From bangham to supercritical fluids. Processes, 8(9), 1022.

Yang, J., Ni, B., Liu, J., Zhu, L., \& Zhou, W. (2011). Application of liposome-encapsulated hydroxycamptothecin in the prevention of epidural scar formation in New Zealand white rabbits. The Spine Journal, 11(3), 218-223.

Zou, L. Q., Liu, W., Liu, W. L., Liang, R. H., Li, T., Liu, C. M., ... \& Liu, Z. (2014). Characterization and bioavailability of tea polyphenol nanoliposome prepared by combining an ethanol injection method with dynamic high-pressure microfluidization. Journal of Agricultural and Food Chemistry, 62(4), 934-941. 